Original article

\title{
Quality of life and risk factors for chronic non-communicable diseases among physicians in Tomsk Oblast
}

\author{
Evgeny S. Kulikov ${ }^{1}$, Alisya A. Almikeeva ${ }^{1}$, Olga S. Kobyakova ${ }^{2}$, Nailya M. Faizulina ${ }^{1}$, Ivan A. Deev ${ }^{1}$, \\ Natalya P. Garganeeva ${ }^{1}$, Nikolay D. Yarovoy ${ }^{1}$, Elena A. Starovoitova ${ }^{1}$, Alexander F. Kanev ${ }^{1}$ \\ ${ }^{1}$ Siberian State Medical University, Tomsk, Russia \\ ${ }^{2}$ Central Research Institute for Health Organization and Informatics, Moscow, Russia
}

Received 27 April 2021, Revised 2 November 2021, Accepted 24 November 2021

(C) 2021, Russian Open Medical Journal

\begin{abstract}
Objective - To investigate the frequency and influence of risk factors (RF) for chronic non-communicable diseases (CNCD) on the quality of life (QoL) among physicians in Tomsk Oblast, depending on their gender, specialty and place of residence.

Material and Methods - The study involved 1,668 physicians from 76 medical institutions. To determine the frequency of RF for CNCD, we employed the questionnaire, Monitoring of Risk Factors for Chronic Non-Communicable Diseases in Practical Healthcare. The QoL level was assessed using the Russian-language version of WHOQOL-BREF.

Results - When assessing QoL, the overall value for physicians was $56.7 \pm 10.3$. The highest average value was obtained in the domain of social relations (68.81 points), whereas the lowest, in the domain of physical health (51.56 points). At the same time, there were no statistically significant differences in the QoL level depending on residence and gender. When studying the effect of RF on QoL, we established that psychological health was higher among doctors without excess body weight living outside the metropolitan area of Tomsk Oblast (54.17 vs. 58.33; $p=0.016$ ). Among female physicians with normal body weight, QoL was higher in the physical health and psychological health domains ( 51.03 vs. $52.25, p=0.04$, and 56.36 vs. $57.79, p=0.04$, respectively). For internists, QoL in the psychological health domain was higher for doctors without excess body weight ( 56.34 vs. $58.54, p=0.017$ ). In diagnosticians, QoL in psychological health domain and environmental factors domain was higher among those who adhered to a rational diet (56.57 vs. $61.50, p=0.01$, and 51.82 vs. 56.33, $\mathrm{p}=0.03$, correspondingly).

Conclusion - The survey has demonstrated low values of the QoL parameters in healthcare workers with a weak association with RF for CNCD. Hence, additional research is needed to identify the factors shaping the QoL formation in this social category.
\end{abstract}

Keywords: risk factors, chronic non-communicable diseases, quality of life, physicians.

Cite as Kulikov ES, Almikeeva AA, Kobyakova OS, Faizulina NM, Deev IA, Garganeeva NP, Yarovoy ND, Starovoitova EA, Kanev AF. Quality of life and risk factors for chronic non-communicable diseases among physicians in Tomsk Oblast. Russian Open Medical Journal $2021 ; 10:$ e0414.

Correspondence to Alisya A. Almikeeva. Phone: +79234261020. E-mail: alisa.almikeeva@gmail.com.

\section{Introduction}

Without doubt, working in the healthcare sector is among the most challenging and demanding professions. It is associated with the impact of various labor factors on a health worker, which may provoke the development of behavioral risk factors (RF), such as smoking, alcohol abuse, unbalanced diet, and low physical activity; these, in turn, lead to the formation of metabolic RF for chronic non-communicable diseases (CNCD) [1].

In domestic and world literature, an issue of the negative impact of RF for CNCD on the quality of life (QoL) does not lose its relevance. According to foreign authors, RFs often potentiate the negative effects of each other. For example, respondents of one of the studies with one, two and three risk factors were 2.2, 3.7 and 5.8 times, respectively, more likely to report dissatisfaction with their lives than respondents without RF [2], i.e., avoiding unhealthy lifestyles not only increases its duration, but also improves its quality.
However, currently, there is no clear understanding of exactly how and to what extent different RF and QoL indicators are associated with each other. Moreover, a very limited number of recent studies were devoted to investigating $\mathrm{RF}$

for CNCD and their influence on various QoL parameters. Whether presence of CNCD correlates with RF is still not known for certain $[3,4]$. An open question remains: how the lifestyle affects the quality of life of medical workers, including physicians. At present, there are no comprehensive studies taking into account the prevalence of $\mathrm{RF}$, along with social and environmental factors of a specific region of the Russian Federation; and even more so, considering the specialty and place of residence of physicians. On the other hand, when developing effective prevention programs, it is essential to be guided by the most precise and specific information.

That is why, the goal of our research project was to compensate for the lack of knowledge about the mechanisms of interaction between RF for CNCD and QoL indicators in physicians, 
and to highlight the most significant RF and susceptible QoL parameters for further preventive programs.

\section{Material and Methods}

\section{Study design}

To assess the frequency and effect of RF for CNCD on QoL in physicians of Tomsk Oblast, a comparative one-stage study was carried out (http://www.ssmu.ru/ru/nauka/projekts/med_work). At the time of the study, the total number of medical workers with higher education in Tomsk and Tomsk Oblast was 5,913, and they were working at public and private medical institutions. A quarter of these doctors were randomly selected for the survey. Hence, we may assume that the obtained data reflected the actual state of affairs in the region [5].

The study protocol was approved by the local Ethics Committee of the Federal State Budgetary Institution of Higher Education Siberian State Medical University of the Russian
Federation Ministry of Healthcare, located in Tomsk (Approval No. 3827 of September 29, 2014). As part of the study, a physician complying with the selection criteria was asked to fill out a questionnaire designed on the basis of the guidelines, 'Monitoring of Risk Factors for Chronic Non-Communicable Diseases in Practical Healthcare', recommended for use by the Ministry of Healthcare of Russia (the official directive dated January 16, 2013, No. 14-2/10/2-123) (Appendix 1) [5], as well as the Russianlanguage version of the Brief Questionnaire of the World Health Organization (WHOQOL-BREF) (Appendix 2) [7]. This questionnaire is built on four domains: physical health, psychological health, social relations, and environmental factors. The replies was assessed on a five-point scale, recalculated sensu the algorithms recommended by the World Health Organization (Appendix 3). The final results were values ranging 1-100 points, calculated separately for each domain [7]. The questionnaire was submitted in electronic form and posted on the website, http://www.golosaonline.ru/medto.

Table 1. The quality of life in physicians of Tomsk Oblast depending on their place of residence

\begin{tabular}{lcccc}
\hline Quality of life (points) & Total, $n=1,668$ & Metropolitan area of Tomsk Oblast, $n=1,320$ & Outside the metropolitan area of Tomsk Oblast, $n=348$ & \multirow{2}{*}{\begin{tabular}{c} 
M \\
\cline { 2 - 4 }
\end{tabular}} \\
\hline Physical health domain & $51.56 \pm 10.44$ & $\mathrm{M} \pm \mathrm{SD}$ & $51.66 \pm 9.94$ & 0.743 \\
Psychological health domain & $56.85 \pm 11.24$ & $56.85 \pm 10.57$ & $56.88 \pm 11.67$ \\
Social relations domain & $65.81 \pm 17.27$ & $66.04 \pm 17.39$ & $64.94 \pm 16.78$ \\
Environmental factors domain & $52.52 \pm 14.59$ & $52.39 \pm 14.55$ & $53.02 \pm 14.74$ & 0.918 \\
\hline
\end{tabular}

Table 2. The quality of life in physicians of Tomsk Oblast depending on their gender

\begin{tabular}{lccc}
\hline Quality of life (points) & Total, $n=1,668$ & Women, $n=1,179$ & $M e n, n=489$ \\
\hline Physical health domain & M \pm SD & M \pm SD & M \\
Psychological health domain & $51.56 \pm 10.44$ & $51.67 \pm 10.40$ & $51.31 \pm 10.51$ \\
Social relations domain & $56.85 \pm 11.24$ & $56.91 \pm 11.34$ & 0.619 \\
Environmental factors domain & $65.81 \pm 17.27$ & $65.72 \pm 17.93$ & 0.820 \\
\hline
\end{tabular}

Table 3. The quality of life in physicians of Tomsk Oblast depending on the presence or absence of risk factors for chronic non-communicable diseases

\begin{tabular}{|c|c|c|c|}
\hline Risk factors / quality of life domains & Quality of life (points), risk factor, $M \pm S D$ & Quality of life (points), no risk factor, $M \pm S D$ & $p$ \\
\hline \multicolumn{4}{|l|}{ Smoking } \\
\hline Physical health domain & $51.79 \pm 11.33$ & $51.60 \pm 10.28$ & 0.660 \\
\hline Psychological health domain & $56.96 \pm 10.57$ & $56.93 \pm 11.32$ & 0.890 \\
\hline Social relations domain & $65.24 \pm 16.41$ & $65.88 \pm 17.38$ & 0.870 \\
\hline Environmental factors domain & $52.41 \pm 15.10$ & $52.56 \pm 14.53$ & 0.981 \\
\hline \multicolumn{4}{|l|}{ Excessive alcohol consumption } \\
\hline Physical health domain & $50.97 \pm 11.17$ & $51.65 \pm 10.35$ & 0.357 \\
\hline Psychological health domain & $57.29 \pm 10.64$ & $56.80 \pm 11.31$ & 0.734 \\
\hline Social relations domain & $65.41 \pm 16.50$ & $65.85 \pm 17.37$ & 0.678 \\
\hline Environmental factors domain & $52.11 \pm 15.32$ & $52.58 \pm 14.50$ & 0.496 \\
\hline \multicolumn{4}{|l|}{ Poor nutrition } \\
\hline Physical health domain & $51.72 \pm 10.52$ & $51.23 \pm 10.28$ & 0.202 \\
\hline Psychological health domain & $56.98 \pm 11.28$ & $56.60 \pm 11.17$ & 0.498 \\
\hline Social relations domain & $65.75 \pm 17.68$ & $65.94 \pm 16.38$ & 0.541 \\
\hline Environmental factors domain & $52.72 \pm 14.44$ & $52.12 \pm 14.89$ & 0.459 \\
\hline \multicolumn{4}{|l|}{ Sedentary lifestyle } \\
\hline Physical health domain & $51.66 \pm 10.79$ & $51.48 \pm 10.14$ & 0.377 \\
\hline Psychological health domain & $56.54 \pm 11.14$ & $57.12 \pm 11.32$ & 0.323 \\
\hline Social relations domain & $65.98 \pm 17.19$ & $65.67 \pm 17.34$ & 0.832 \\
\hline Environmental factors domain & $52.66 \pm 14.82$ & $52.41 \pm 14.40$ & 0.642 \\
\hline \multicolumn{4}{|l|}{ Excess body weight } \\
\hline Physical health domain & $51.51 \pm 10.04$ & $52.08 \pm 10.11$ & 0.016 \\
\hline Psychological health domain & $56.44 \pm 10.59$ & $57.70 \pm 11.52$ & 0.048 \\
\hline Social relations domain & $65.44 \pm 16.38$ & $66.55 \pm 17.50$ & 0.403 \\
\hline Environmental factors domain & $53.12 \pm 14.74$ & $53.01 \pm 14.96$ & 0.270 \\
\hline \multicolumn{4}{|l|}{ High blood pressure } \\
\hline Physical health domain & $52.45 \pm 10.47$ & $51.32 \pm 10.43$ & 0.078 \\
\hline Psychological health domain & $56.95 \pm 11.19$ & $56.83 \pm 11.26$ & 0.820 \\
\hline Social relations domain & $64.62 \pm 17.60$ & $66.13 \pm 17.17$ & 0.114 \\
\hline Environmental factors domain & $51.81 \pm 14.46$ & $52.71 \pm 14.62$ & 0.277 \\
\hline
\end{tabular}




\section{Participants}

The respondents with higher medical education, working on the territory of Tomsk Oblast, were asked to voluntarily fill out an online questionnaire. The total of 1,668 doctors from 76 medical establishments of Tomsk Oblast of all types of ownership and different affiliation took part in the survey. These included 20 institutions for medical treatment and disease prevention in the district centers of Tomsk Oblast, 55 medical organizations in the metropolitan area of Tomsk, and one institution in the closed city of Seversk.

All doctors participating in the study were stratified into four large groups in accordance with their specialty. The first group (Internists) encompassed the specialties related to internal, including cardiologists, pediatricians, physical therapists, dentists, general practitioners, otorhinolaryngologists, neurologists, infectious disease specialists, nephrologists, pulmonologists, gastroenterologists, district psychiatrists and narcologists, clinical pharmacologists, endocrinologists, phthisiologists, etc.

Table 4. Multivariate linear regression analysis. Relationship between risk factors and quality of life in the psychological health domain in physicians

\begin{tabular}{llll}
\hline Risk factor & $B$ & $S E$ & $P$ \\
\hline Body weight & -1.07 & 1.02 & $0.02^{*}$ \\
Eating vegetables and fruits & 0.22 & 0.72 & 0.76 \\
Low physical activity & -0.81 & 0.69 & 0.24 \\
Alcohol consumption & 0.30 & 1.37 & 0.83 \\
\hline
\end{tabular}

* statistically significant differences. $\mathrm{R}^{2}=0.007 ; \mathrm{p}=0.05$.
The second group (Surgeons) included medical specialties of the surgical field: obstetricians/gynecologists, anesthetists/resuscitators, traumatologists/orthopedists, coloproctologists, surgeons, urologists, etc.

The third group (Diagnosticians) included the following specialties: radiologists, diagnostic medical sonographer, functional medicine doctors, laboratory assistants, and clinical laboratory diagnosticians. The fourth group incorporated the specialties of organizational and methodological scope: statisticians, heads of structural divisions of medical institutions, as well as chief polyclinic and hospital administrators.

\section{Data collection}

In addition, doctors indicated their anthropometric data for calculating body mass index (BMI), blood pressure (BP), and also entered the information on glucose content and blood cholesterol level obtained during their last medical examination. Excess body weight was recorded at $\mathrm{BMI} \geq 25 \mathrm{~kg} / \mathrm{m}^{2}$. Hypercholesterolemia and hyperglycemia were recorded at total cholesterol $>5.0 \mathrm{mmol} / \mathrm{L}$ and blood glucose at $\geq 6.1 \mathrm{mmol} / \mathrm{L}$, respectively. Increased BP was additionally measured if the respondent indicated it at a value $\geq 140 / 90 \mathrm{~mm} \mathrm{Hg}$ [6].

For the population of healthcare workers, the cutoff value of possible QoL deterioration was not previously proposed; therefore, the recommended for healthy populations value of $75.0 \pm 2.5 \%$ of the maximum measurement scale was used as a threshold value in this study [8].

Table 5. The quality of life in physicians of Tomsk Oblast depending on their specialty

\begin{tabular}{|c|c|c|c|c|}
\hline $\begin{array}{l}\text { Risk factors / quality of life } \\
\text { domains }\end{array}$ & $\begin{array}{l}\text { Internists: } \\
\text { Quality of life, points (risk } \\
\text { factor) vs. points (no risk } \\
\text { factor); } p\end{array}$ & $\begin{array}{l}\text { Surgeons: } \\
\text { Quality of life, points (risk } \\
\text { factor) vs. points (no risk } \\
\text { factor); } p\end{array}$ & $\begin{array}{l}\text { Diagnosticians: } \\
\text { Quality of life, points (risk } \\
\text { factor) vs. points (no risk } \\
\text { factor); } p\end{array}$ & $\begin{array}{c}\text { Healthcare administrators: } \\
\text { Quality of life, points (risk } \\
\text { factor) vs. points (no risk } \\
\text { factor); } p\end{array}$ \\
\hline \multicolumn{5}{|l|}{ Smoking } \\
\hline Physical health domain & 52.50 vs. $51.69 ; p=0.349$ & 51.63 vs. $51.57 ; p=0.887$ & 52.44 vs. $51.53 ; p=0.561$ & 47.42 vs. $50.84 ; p=0.244$ \\
\hline Psychological health domain & 56.89 vs. $57.34 ; p=0.855$ & 57.00 vs. $55.86 ; p=0.271$ & 58.20 vs. $58.07 ; p=0.955$ & 55.00 vs. $53.91 ; p=0.701$ \\
\hline Social relations domain & 65.80 vs. $65.95 ; p=0.592$ & 65.45 vs. $65.97 ; p=0.655$ & 65.68 vs. $66.20 ; p=0.902$ & 58.92 vs. $63.96 ; p=0.515$ \\
\hline \multicolumn{5}{|l|}{ Excessive alcohol consumption } \\
\hline Physical health domain & 51.81 vs. $51.64 ; p=0.520$ & 50.92 vs. $51.86 ; p=0.181$ & 48.61 vs. $51.72 ; p=0.420$ & 47.75 vs. $50.54 ; p=54.44$ \\
\hline Psychological health domain & 56.68 vs. $57.20 ; p=0.623$ & 58.04 vs. $55.90 ; p=0.060$ & 58.76 vs. $58.09 ; p=0.859$ & 51.62 vs. $54.44 ; p=0.330$ \\
\hline Social relations domain & 64.22 vs. $66.10 ; p=0.496$ & 65.52 vs. $66.09 ; p=0.676$ & 73.07 vs. $65.93 ; p=0.182$ & 62.50 vs. $62.14 ; p=0.960$ \\
\hline Environmental factors domain & 50.38 vs. $52.89 ; p=0.922$ & 54.09 vs. $52.07 ; p=0.200$ & 49.69 vs. $53.53 ; p=0.400$ & 48.62 vs. $49.90 ; p=0.428$ \\
\hline \multicolumn{5}{|l|}{ Poor nutrition } \\
\hline Physical health domain & 51.84 vs. $51.31 ; p=0.268$ & 51.97 vs. $50.85 ; p=0.299$ & 51.42 vs. $51.66 ; p=0.894$ & 49.79 vs. $51.42 ; p=0.698$ \\
\hline Psychological health domain & 57.48 vs. $56.59 ; p=0.305$ & 56.90 vs. $56.74 ; p=0.301$ & 56.57 vs. $61.50 ; p=0.011$ & 53.55 vs. $55.64 ; p=0.272$ \\
\hline Environmental factors domain & 53.23 vs. $51.73 ; p=0.088$ & 52.91 vs. $51.20 ; p=0.549$ & 51.82 vs. $56.33 ; p=0.032$ & 48.71 vs. $52.21 ; p=0.326$ \\
\hline \multicolumn{5}{|l|}{ Sedentary lifestyle } \\
\hline Physical health domain & 51.98 vs. $51.43 ; p=0.125$ & 51.28 vs. $52.04 ; p=0.431$ & 51.46 vs. $51.55 ; p=1.000$ & 51.60 vs. $49.02 ; p=0.276$ \\
\hline Psychological health domain & 57.06 vs. $57.24 ; p=0.839$ & 55.75 vs. $56.82 ; p=0.313$ & 57.46 vs. $58.98 ; p=0.442$ & 54.53 vs. $53.86 ; p=0.981$ \\
\hline Social relations domain & 66.77 vs. $65.40 ; p=0.157$ & 64.96 vs. $67.04 ; p=0.943$ & 66.43 vs. $66.43 ; p=0.751$ & 64.17 vs. $60.21 ; p=0.474$ \\
\hline Environmental factors domain & 52.79 vs. $52.64 ; p=0.591$ & 52.08 vs. $52.77 ; p=0.549$ & 53.86 vs. $52.53 ; p=0.484$ & 52.06 vs. $47.56 ; p=0.276$ \\
\hline \multicolumn{5}{|l|}{ Excess body weight } \\
\hline Physical health domain & 50.95 vs. $52.06 ; p=0.155$ & 50.45 vs. $52.34 ; p=0.148$ & 51.57 vs. $51.67 ; p=0.717$ & 46.19 vs. $52.45 ; p=0.063$ \\
\hline Psychological health domain & 56.34 vs. $58.54 ; p=0.017$ & 55.14 vs. $65.68 ; p=0.338$ & 61.00 vs. $56.97 ; p=0.927$ & 53.04 vs. $52.70 ; p=0.891$ \\
\hline Social relations domain & 66.42 vs. $67.08 ; p=0.690$ & 65.50 vs. $66.32 ; p=0.666$ & 65.02 vs. $66.35 ; p=0.454$ & 61.66 vs. $60.41 ; p=0.954$ \\
\hline Environmental factors domain & 51.98 vs. $53.51 ; p=0.150$ & 52.78 vs. $52.51 ; p=0.826$ & 54.02 vs. $52.28 ; p=0.556$ & 47.47 vs. $50.37 ; p=0.616$ \\
\hline \multicolumn{5}{|l|}{ High blood pressure } \\
\hline Physical health domain & 53.23 vs. $52.20 ; p=0.623$ & 52.13 vs. $51.81 ; p=0.591$ & 50.12 vs. $51.77 ; p=0.672$ & 50.06 vs. $50.34 ; p=0.642$ \\
\hline Psychological health domain & 57.65 vs. $57.24 ; p=0.569$ & 55.95 vs. $56.42 ; p=0.800$ & 58.29 vs. $58.11 ; p=0.675$ & 56.68 vs. $53.66 ; p=0.350$ \\
\hline Social relations domain & 65.22 vs. $66.15 ; p=0.347$ & 63.97 vs. $66.58 ; p=1.135$ & 64.32 vs. $66.85 ; p=0.714$ & 62.43 vs. $62.12 ; p=0.504$ \\
\hline Environmental factors domain & 52.00 vs. $52.89 ; p=0.634$ & 54.07 vs. $53.18 ; p=0.923$ & 52.03 vs. $53.51 ; p=0.652$ & 52.43 vs. $49.22 ; p=0.416$ \\
\hline
\end{tabular}




\section{Statistics}

For statistical data processing, we used the Statistica for Windows software package, version 10.0. To determine the significance of differences in pairwise unrelated samples, the Mann-Whitney $U$ test was employed. The null hypothesis (no difference in values between groups) was rejected at $p<0.05$. Also, multivariate linear regression analysis was performed to assess the value of the contribution of each RF for CNCD to each QoL domain.

\section{Results}

When assessing QoL, the total value for physicians altogether was $56.7 \pm 10.3$. The highest average value was obtained in domain of social relations (68.81 points), whereas the lowest score was detected in the physical health domain (51.56 points). We also examined the differences in QoL depending on the place of residence and employment of physicians (Table 1), and also on their gender (Table 2). According to our calculations, the value for all four QoL domains can be evaluated as reduced, even though statistically significant differences among the compared parameters were not revealed.

To determine the association of RF for CNCD and QoL in doctors, we have also estimated the RF frequencies. Poor/inappropriate nutrition was recorded in more than half of physicians $(67.6 \%, n=1,128)$. Sedentary lifestyle was registered in almost $45.7 \%$ of respondents $(n=762)$. Excess body weight was characteristic for $34.7 \%$ of doctors $(n=388)$. Elevated blood pressure was found in $21.2 \%(n=354)$ of the respondents in Tomsk Oblast. Tobacco smoking among doctors in Tomsk Oblast was recorded at the level of $15.1 \%(n=253)$. Such $R F$ as alcohol abuse (drinking alcoholic beverages $>2$ times in the last 2 weeks) was registered in $11.2 \%$ of respondents $(n=186)$. Hyperglycemia was detected in only $1.6 \%(n=20)$ of doctors. As for blood glucose level, $26.9 \%$ did not know theirs. Hypercholesterolemia was found in every fourth physician $(27.3 \%, n=297)$. The cholesterol level was indicated in the questionnaire by $34.8 \%$ of doctors.

Next, we compared the QoL values in doctors with and without RF (Table 3). Due to the fact that hyperglycemia and hypercholesterolemia were indicated by just a small proportion of participants, we did not evaluate the association of these RF with QoL in physicians. According to our data, QoL in doctors without RF for CNCD ( $n=55)$ did not differ statistically significantly from QoL in their colleagues with at least one RF $(n=388)$. However, we established that QoL in the physical and psychological health domains was higher in doctors without excess body weight ( $p=0.016$ and $p=0.031$, correspondingly).

We also examined the QoL of physicians, men and women, depending on the presence or absence of RF and on the place of work. As a result, it was established that QoL in the psychological health domain was higher among physicians without excess body weight living outside the metropolitan area of the region ( $54.17 \mathrm{vs}$. 58.33; $p=0.016$ ). Among female physicians with a normal boy weight, QoL was higher in the physical and psychological health domains ( 51.03 vs. $52.25, p=0.04$, and 56.36 vs. $57.79, p=0.04$, respectively). In individuals with higher medical education, excess body weight was an independent predictor of a decrease in the score of the psychological health domain (Table 3). Other domains showed no significant associations with any of the risk factors.

The following differences in QoL were detected depending on the presence or absence of RF in various medical specialties
(Tables 4 and 5). For example, among internists, QoL in the domain of psychological health was higher among doctors without excess body weight ( 56.34 vs. $58.54, p=0.017$ ). It was revealed that in the group of diagnosticians, QoL in the domains of psychological health and environmental factors was higher among those who adhered to a rational diet ( 56.57 vs. $61.50, p=0.01$, and 51.82 vs. $56.33, p=0.03$, correspondingly).

\section{Discussion}

Our data demonstrated that the physicians in Tomsk Oblast exhibited a low level of QoL, compared with the general population of Siberian Federal District or Central Federal District (56.7 vs. 61.11 or 61.34 , respectively) [9]. On the contrary, the frequencies of such RF for CNCD, as inappropriate nutrition, low physical activity and excess body weight were higher than the national average values [10].

We did not reveal significant differences between QoL in doctors of different genders, even though scientists from India proved that QoL indicators in the domains of physical and psychological health, as well as social relations, were significantly higher in male doctors, compared with female physicians $(p<0.05)$. However, an overall QoL was assessed as good in 743 (64.4\%), and very good in 324 (28.1\%), respondents [11]. Scientists from China have also noted that QoL in all domains was significantly lower in women than in men $(p<0.001)$. The authors from Brazil who studied the QoL of otorhinolaryngologists also stated that men had better QoL indicators in the psychological health domain, compared with women ( $p=0.013)$ [3]. According to Mello et al, it was established that orthopedic physicians had high QoL values in the domains of physical health (63.89) and environmental factors (65.77) [4].

To date, there is a limited amount of data in the published sources on the effect of lifestyle on QoL indicators in the healthcare workers. For example, the study by Teles et al. $(n=797)$ revealed that smokers had lower rates in the environmental factors and social relations domains: OR 3.13 (95\% Cl 1.38-7.11). Physicians with sedentary lifestyles had overall reduced QoL (OR 2.00 (95\% Cl 1.06-3.81) [12].

However, the data of our study implied that the level of QoL was low and did not have a significant correlation with RF for CNCD in the population of medical workers. Hence, with a high degree of assurance, it can be argued that low QoL values were due to the presence of other factors.

Using published studies, we have analyzed the possible causes of unhealthy lifestyles that could subsequently have a detrimental effect on the QoL of healthcare workers. Many foreign authors suggested that low social status, low wages and long working hours were the factors having a negative impact on the QoL of physicians to a much greater extent $(p<0.001)$ [13], whereas the proportion of night shifts in the irregular shift-based work schedule was a predictor of excess body weight. Scientists also reported that low QoL (43.06-58.51 points) was associated with dissatisfaction of their work and stress, which was the case in $74.6 \%$ of primary healthcare physicians in China [13]. The same conclusion was formulated by scientists from Jordan, Jaradat R. et al, who detected that the above listed labor factors constituted a trigger for the emergence of smoking (35.3\%), overweight status (41.3\%), and obesity (18.4\%) [14]. Besides, scientists from Croatia, Klasan et al., recorded that low indicator values in the domain of 
physical health were a consequence of low working capacity $(p<0.001)$ among physicians [15].

\section{Study Limitations}

As a result of our study, a quarter of medical workers were randomly surveyed; hence, we can assume that the obtained data reflected the actual state of affairs in the region. However, the respondent's place of employment was not taken into account for example, whether he/she worked at a hospital or at a polyclinic. It should also be noted that hyperglycemia and hypercholesterolemia were indicated only by a small proportion of the survey participants; consequently, the association of these RF for CNCD with the QoL in physicians was not analyzed.

\section{Conclusion}

Our study has demonstrated low values of the QoL parameters in medical workers, and those parameters exhibited a weak association with RF for CNCD. Therefore, additional studies are needed to identify the factors determining the formation of QoL in this social category. Also, our study has demonstrated the need for the development of special preventive programs for physicians, in terms of $\mathrm{CNCD}$, taking into account the specifics of their work.

\section{Funding}

The study was carried out with the financial support of the Russian Foundation for Basic Research within the framework of a scientific project No. 19-313-90046.

\section{Conflict of Interest}

The authors declare that they have no conflicts of interest.

\section{References}

1. World Health Organization. World health statistics 2017: monitoring health for the SDGs, sustainable development goals. Geneva: WHO. 2017; 116 p. https://apps.who.int/iris/handle/10665/255336.

2. Li K, Hüsing $A$, Kaaks R. Lifestyle risk factors and residual life expectancy at age 40: A German cohort study. BMC Med 2014; 12: 59. https://doi.org/10.1186/1741-7015-12-59.

3. Rezende GL, Sarmet M, Granjeiro RC, Nakanishi M, de Oliveira CAPC The quality of life among otorhinolaryngology residents in Distrito Federal (Brazil). Braz J Otorhinolaryngol 2011; 77(4): 466-472. English, Portuguese. https://doi.org/10.1590/s1808-86942011000400010.

4. Mello MH, Souza JC. Quality of life of orthopedists in Mato Grosso do Sul. Rev Bras Ortop 2013; 48(1): 92-99. https://doi.org/10.1016/j.rboe.2012.04.002.

5. Tomsk Oblast Branch of the Federal Service for State Statistics for. The number of healthcare workers. 2021.2 Russian. https://tmsk.gks.ru/storage/mediabank/Численность\%20медицинск их\%20работников(3).pdf.

6. Balanova YuA, Imaeva AE, Kontsevaya AV, Shalnova SA, Deev AD, Kapustina $\mathrm{AV}$, et al. Epidemiological monitoring of risk factors of chronic non-communicable diseases in public health practice at the regional level. Guidelines. Moscow: Media Sphera. 2016; 111 p. Russian. https://elibrary.ru/item.asp?id=26641844.

7. WHOQOL-BREF. Introduction, administration, scoring and generic version of the assessment. Field Trial Version. Programme on mental health. Geneva: WHO. 1996; 18 p. http://www.who.int/mental_health/media/en/76.pdf.

8. Cummins RA. On the trail of the gold standard for subjective wellbeing. Soc Indic Res 1995; 35: 179-200. http://doi.org/10.1007/BF01079026.
9. Tutelyan VA, Nikityuk DB, Buriak DA, Akolzina SE, Baturin AK, Eds. translated by Kishko, O.N. Quality of Life. Health and Nutrition. Atlas in Russian and English languages. Moscow: Medicine 2018; 696 p. Russian, English.

10. Muromtseva GA, Kontsevaya AV, Konstantinov VV, Artamonova GV Gatagonova TM, Duplyakov DV, et al. The prevalence of non-infectious diseases risk factors in russian population in 2012-2013 years. The results of ECVD-RF. Cardiovascular Therapy and Prevention. 2014; 13(6): 4-11. Russian. https://doi.org/10.15829/1728-8800-2014-6-411.

11. Ghazanfar H, Iqbal S, Naseem S. Quality of life of post-graduate medical students working in private and public hospitals in Punjab as measured by WHOQOL-BREF questionnaire. J Pak Med Assoc 2018; 68(6): 908-913. https://pubmed.ncbi.nlm.nih.gov/30325910.

12. Teles MA, Barbosa MR, Vargas AM, Gomes VE, Ferreira EF, Martins AM, et al. Psychosocial work conditions and quality of life among primary health care employees: A cross sectional study. Health Qual Life Outcomes 2014; 12: 72. https://doi.org/10.1186/1477-7525-12-72.

13. Liang $Y$, Wang $H$, Tao $X$. Quality of life of young clinical doctors in public hospitals in China's developed cities as measured by the Nottingham Health Profile (NHP). Int J Equity Health 2015; 14: 85. https://doi.org/10.1186/s12939-015-0199-2.

14. Asante JO, Li MJ, Liao J, Huang YX, Hao YT. The relationship between psychosocial risk factors, burnout and quality of life among primary healthcare workers in rural Guangdong Province: A cross-sectional study. BMC Health Serv Res 2019; 19(1): 447. https://doi.org/10.1186/s12913-019-4278-8.

15. Jaradat $R$, Lahlouh $A$, Mustafa $M$. Sleep quality and health related problems of shift work among resident physicians: A cross-sectional study. Sleep Med 2020; 66: 201-206. https://doi.org/10.1016/j.sleep.2019.11.1258.

16. Klasan A, Madzarac G, Milosevic M, Mustajbegovic J, Keleuva S. Predictors of lower work ability among emergency medicine employees: the Croatian experience. Emerg Med J 2013; 30(4): 275 279. https://doi.org/10.1136/emermed-2011-200780.

\section{Authors:}

Evgeny S. Kulikov - MD, DSc, Professor, Department of General Medical Practice and Polyclinic Therapy, Siberian State Medical University, Tomsk, Russia. https://orcid.org/0000-0002-0088-9204.

Alisya A. Almikeeva - Graduate Student, Siberian State Medical University, Tomsk, Russia. https://orcid.org/0000-0001-9911-200X

Olga S. Kobyakova - MD, DSc, Professor, Director of Central Research Institute for Health Organization and Informatics, Moscow, Russia https://orcid.org/0000-0003-0098-1403.

Nailya M. Fayzulina - Instructor, Department of General Medical Practice and Polyclinic Therapy, Siberian State Medical University, Tomsk, Russia. http://orcid.org/0000-0001-9750-5352.

Ivan A. Deev - MD, DSc, Professor, Department of General Medical Practice and Polyclinic Therapy, Siberian State Medical University, Tomsk, Russia. https://orcid.org/0000-0002-4449-4810.

Natalya P. Garganeeva - DSc, Professor, Department of General Medical Practice and Polyclinic Therapy, Siberian State Medical University, Tomsk, Russia. https://orcid.org/0000-0002-7353-7154.

Nikolay D. Yarovoy - Undergraduate Student, Siberian State Medical University, Tomsk, Russia. https://orcid.org/0000-0003-3619-6095.

Elena A. Starovoytova - MD, PhD, Assistant Professor, Department of General Medical Practice and Polyclinic Therapy, Siberian State Medical University, Tomsk, Russia. https://orcid.org/0000-0001-8283-2238.

Alexander F. Kanev - Instructor, Department of Propaedeutics of Internal Medicine, Siberian State Medical University, Tomsk, Russia. https://orcid.org/0000-0001-9612-8815. 


\section{Appendix 1. Individual registration card of the examinee for identification of risk factors for chronic non-communicable diseases (general module)}

\section{Questionnaire}

\section{General information}

Territory code:

Patient number:

Full name of the examinee:

Clinic number:

Site number:

Examination date:

Date of Birth:

Gender:

\section{male (1)}

female (2)

Marital status:

$$
\begin{aligned}
& \text { never married before (1) } \\
& \text { married / cohabitation ( } 2 \text { ) } \\
& \text { divorced / separated ( } 3 \text { ) }
\end{aligned}
$$

Education:

widower / widow (4)

Primary (1)

Incomplete secondary (2)

Secondary (3)

Higher (4)

Years of study:

\section{Behavioral habits}

\section{Nutrition}

Do you salt prepared food?

No (1)

Yes, after tasting it first (2)

Yes, without tasting it first (3)

Do you eat about 400 grams (or $4-5$ servings) of fruits and vegetables daily (not including potatoes):

$$
\text { No (1) }
$$

Yes (2)

Do you consume six or more lumps (teaspoons) of sugar, jam, honey and other sweets per day?

$$
\text { No (1) }
$$

Yes (2)

Do you pay attention to the fat and/or cholesterol content of foods when buying (on labels or packaging), or when cooking?

$$
\begin{aligned}
& \text { No (1) } \\
& \text { Yes (2) }
\end{aligned}
$$

Physical exercise

How many minutes per day do you spend walking at a moderate or fast pace (including travel to and from work)?

$$
\text { Under } 30 \min (1)
$$$$
30 \text { min and more (2) }
$$

\section{Smoking}

Your smoking status:

$\square \quad$ Never smoked (1) [Interviewer: Proceed to the Drinking Alcohol section]

Quit (2)

I smoke (3)

If yes, do/did you use tobacco products on a daily basis?

$$
\text { No (1) }
$$$$
\text { Yes (2) }
$$

At what age you started smoking? remember, then how long ago did this happen? years old; If you do not

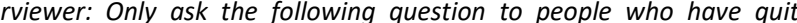
smoking]

At what age did you quit smoking? remember, then how long ago did this happen? years old; If you do not

On average, how many cigarettes (or other tobacco products) do/did you smoke per day?

\section{Alcohol consumption}

Ever felt like you need to reduce your alcohol consumption?

$$
\begin{aligned}
& \text { No (1) } \\
& \text { Yes (2) }
\end{aligned}
$$

Are you annoyed by questions about your drinking?

$$
\square \quad \text { No (1) }
$$$$
\text { Yes (2) }
$$

Do you feel guilty about how much you drink?

$$
\text { No (1) }
$$$$
\text { Yes (2) }
$$

Do you deal with a hangover in the mornings?

$$
\begin{aligned}
& \text { No (1) } \\
& \text { Yes (2) }
\end{aligned}
$$

Do you drink beer?

$$
\text { Yes (1) }
$$$$
\text { No (2) }
$$

If YES, how much did you drink in the last week?

Do you drink dry wine, champagne?

$$
\begin{aligned}
& \text { Yes (1) } \\
& \text { No (2) }
\end{aligned}
$$

If YES, how much did you drink in the last week?

Do you drink fortified wine?

$$
\begin{aligned}
& \text { Yes (1) } \\
& \text { No (2) }
\end{aligned}
$$

If YES, how much did you drink in the last week?

Do you drink homemade spirits?

$$
\begin{aligned}
& \text { Yes (1) } \\
& \text { No (2) }
\end{aligned}
$$

If YES, how much did you drink in the last week?

Do you drink vodka, cognac or other strong drinks?

$$
\begin{aligned}
& \text { Yes (1) } \\
& \text { No (2) }
\end{aligned}
$$

If YES, how much did you drink in the last week?

Refusing to answer about alcohol consumption.

Health and ailments

How do you assess your current state of health overall?

$$
\begin{aligned}
& \text { Excellent (1) } \\
& \text { Very good (2) } \\
& \text { Good (3) } \\
& \text { Satisfactory (4) } \\
& \text { Bad (5) }
\end{aligned}
$$

Do you know your blood pressure?

$$
\begin{aligned}
& \text { No (1) } \\
& \text { Yes (2) }
\end{aligned}
$$

Have a doctor or other healthcare professional ever told you that you have high blood pressure?

$$
\begin{aligned}
& \text { No (1) } \\
& \text { Yes (2) }
\end{aligned}
$$

Have you taken any blood pressure medications in the past two weeks?

$$
\text { No (1) }
$$$$
\text { Yes (2) }
$$

Did your doctor tell you that you have high blood sugar?

$\square \quad$ No (1)

$\square \quad$ Yes (2)

In the past two weeks, have you taken any blood sugar lowering medications?

$$
\text { No (1) }
$$

Yes (2) 
Do you know your cholesterol level?

$$
\text { No (1) }
$$$$
\text { Yes (2) }
$$

Did your doctor tell you that you have high cholesterol?

$$
\begin{aligned}
& \text { No (1) } \\
& \text { Yes (2) }
\end{aligned}
$$

Has a doctor ever told you that you have (had) the following diseases?

\begin{tabular}{llll}
\hline & No & Yes & I do not know \\
\hline Chronic bronchitis & 1 & 2 & 3 \\
Bronchial asthma & & & \\
Stroke & & & \\
Myocardial infarction & & \\
Coronary artery disease (angina pectoris) & & \\
Oncological diseases & & \\
Type 1 diabetes mellitus & & \\
Type 2 diabetes mellitus & & \\
\hline
\end{tabular}

\section{Objective data of the physical examination}

BLOOD PRESSURE

First measurement on the right arm $\mathrm{mmHg}$

Interviewer! If the measurement cannot be taken on the right arm, take it on the left arm and put a check:

Radial pulse, first measurement___ beats per minute BLOOD PRESSURE

Second measurement on the right arm $\mathrm{mmHg}$

Interviewer! If the measurement cannot be taken on the right arm, take it on the left arm and put a check:

Radial pulse, second measurement ___ beats per minute

HEIGHT (standing, with a precision of $0.5 \mathrm{~cm}$ )

CM

WEIGHT (body weight, with a precision of $0.1 \mathrm{~kg}$ ) $\mathrm{kg}$

Waist circumference (with a precision of $0.5 \mathrm{~cm}$ ) $\mathrm{cm}$

Laboratory data

Total cholesterol: $\quad \mathrm{mmol} / \mathrm{L}$

Blood glucose: 
Appendix 2. Quality of life. WHOQOL-BREF questionnaire

Instructions

The following questions concern your point of view on the quality of life, on the state of health and other areas of your life. Please answer all questions. Please choose the answer that works best for you. If you are not sure how to answer a question, the first answer that comes to your mind is often the best one.

Please be mindful of your standards, hopes, entertainment, and interests. We ask how you see your life over the past two weeks. For example, referring to the last two weeks, you answer the question:

\begin{tabular}{|c|c|c|c|c|c|}
\hline & Not at all & Mostly no & It depends & Mostly yes & Yes \\
\hline Do you receive any support from others when you need it? & 1 & 2 & 3 & $(4)$ & 5 \\
\hline
\end{tabular}

You should choose the answer that best describes the degree of support you have received from others in the last two weeks. Therefore, you should select Mostly yes if you received most of the support you needed from others.

\begin{tabular}{lccccc}
\hline Do you receive any support from others when you need it? & Notall & Mostly no & It depends & Mostly yes & Yes \\
\hline
\end{tabular}

You should choose Not at all if you did not receive any support that you needed from others in the last two weeks.

\begin{tabular}{|c|c|c|c|c|c|c|c|}
\hline & & Very poor & Poor & Neither poor nor good & Good & & Very good \\
\hline & How do you rate your quality of life? & 1 & 2 & 3 & 4 & & 5 \\
\hline 1. & & Very dissatisfied & Dissatisfied & Neither satisfied no & ied & Satisfied & Very satisfied \\
\hline 2. & How satisfied are you with your health? & 1 & 2 & 3 & & 4 & 5 \\
\hline
\end{tabular}

Replying to the following questions, indicate how much you have experienced certain conditions in the last two weeks.

\begin{tabular}{|c|c|c|c|c|c|c|}
\hline & & Not at all & A little & Moderately & Very much & Fully \\
\hline 3. & In your opinion, to what extent the physical pain prevents you from doing what you need to? & 1 & 2 & 3 & 4 & 5 \\
\hline 4. & How much do you need any medical assistance to normally function in your daily life? & 1 & 2 & 3 & 4 & 5 \\
\hline 5. & How much do you enjoy life? & 1 & 2 & 3 & 4 & 5 \\
\hline 6. & In your opinion, to what extent your life is meaningful? & 1 & 2 & 3 & 4 & 5 \\
\hline 7. & How well are you able to concentrate? & 1 & 2 & 3 & 4 & 5 \\
\hline 8. & How safe do you feel in your everyday life? & 1 & 2 & 3 & 4 & 5 \\
\hline 9. & How healthy is your physical environment? & 1 & 2 & 3 & 4 & 5 \\
\hline
\end{tabular}

The following questions ask about how completely you experienced or were able to fulfill certain functions in the last two weeks

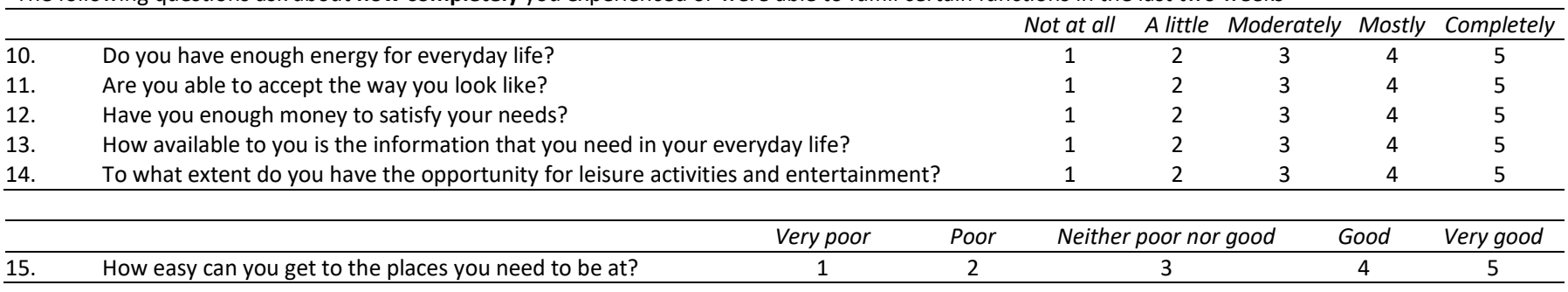

In your answers to the following questions indicate how good or satisfied you have felt about various aspects of your life in the last two weeks

\begin{tabular}{|c|c|c|c|c|c|c|}
\hline & & $\begin{array}{c}\text { Very } \\
\text { dissatisfied }\end{array}$ & Dissatisfied & $\begin{array}{c}\text { Neither satisfied nor } \\
\text { dissatisfied }\end{array}$ & Satisfied & $\begin{array}{c}\text { Very } \\
\text { satisfied }\end{array}$ \\
\hline 16. & How satisfied are you with your sleep? & 1 & 2 & 3 & 4 & 5 \\
\hline 17. & How satisfied are you with your ability to perform your daily living activities? & 1 & 2 & 3 & 4 & 5 \\
\hline 18. & How satisfied are you with your capacity for work? & 1 & 2 & 3 & 4 & 5 \\
\hline 19. & How satisfied are you with yourself? & 1 & 2 & 3 & 4 & 5 \\
\hline 20. & How satisfied are you with your personal relationships? & 1 & 2 & 3 & 4 & 5 \\
\hline 21. & How satisfied are you with your sex life? & 1 & 2 & 3 & 4 & 5 \\
\hline 22. & How satisfied are you with the support from your friends? & 1 & 2 & 3 & 4 & 5 \\
\hline 23. & How satisfied are you with the conditions of your living place? & 1 & 2 & 3 & 4 & 5 \\
\hline 24. & How satisfied are you with your access to health services? & 1 & 2 & 3 & 4 & 5 \\
\hline 25. & How satisfied are you with your transport? & 1 & 2 & 3 & 4 & 5 \\
\hline
\end{tabular}

The following question refers to how often you have felt or experienced certain conditions in the last two weeks.

\begin{tabular}{|c|c|c|c|c|c|c|}
\hline & & Never & Seldom & Quite often & Very often & Always \\
\hline 26. & How often have you had negative feelings, such as bad mood, despair, anxiety, depression? & 1 & 2 & 3 & 4 & 5 \\
\hline
\end{tabular}

\section{THANK YOU FOR YOUR COOPERATION!}

This translation was not created by the World Health Organization (WHO). WHO is not responsible for the content or accuracy of this translation. In the event of any inconsistency between the English and the translated version, the original English version shall be the binding and authentic version. 
Appendix 3. Method for converting raw scores to transformed scores

\begin{tabular}{|c|c|c|}
\hline \multicolumn{3}{|c|}{ DOMAIN 1} \\
\hline \multirow[t]{2}{*}{$\begin{array}{l}\text { Raw } \\
\text { Score }\end{array}$} & \multicolumn{2}{|c|}{$\begin{array}{l}\text { Trasnformed } \\
\text { scores }\end{array}$} \\
\hline & $4-20$ & $0-100$ \\
\hline 7 & 4 & 0 \\
\hline 8 & 5 & 6 \\
\hline 9 & 5 & 6 \\
\hline 10 & 6 & 13 \\
\hline 11 & 6 & 13 \\
\hline 12 & 7 & 19 \\
\hline 13 & 7 & 19 \\
\hline 14 & 8 & 25 \\
\hline 15 & 9 & 31 \\
\hline 16 & 9 & 31 \\
\hline 17 & 10 & 38 \\
\hline 18 & 10 & 38 \\
\hline 19 & 11 & 44 \\
\hline 20 & 11 & 44 \\
\hline 21 & 12 & 50 \\
\hline 22 & 13 & 56 \\
\hline 23 & 13 & 56 \\
\hline 24 & 14 & 63 \\
\hline 25 & 14 & 63 \\
\hline 26 & 15 & 69 \\
\hline 27 & 15 & 69 \\
\hline 28 & 16 & 75 \\
\hline 29 & 17 & 81 \\
\hline 30 & 17 & 81 \\
\hline 31 & 18 & 88 \\
\hline 32 & 18 & 88 \\
\hline 33 & 19 & 94 \\
\hline 34 & 19 & 94 \\
\hline 35 & 20 & 100 \\
\hline
\end{tabular}

\begin{tabular}{|c|c|c|c|c|c|}
\hline \multicolumn{3}{|c|}{ DOMAIN 2} & \multicolumn{3}{|c|}{ DOMAIN 3} \\
\hline \multirow[t]{2}{*}{$\begin{array}{l}\text { Raw } \\
\text { score }\end{array}$} & \multicolumn{2}{|c|}{$\begin{array}{c}\text { Trasnformed } \\
\text { scores }\end{array}$} & \multirow[t]{2}{*}{$\begin{array}{l}\text { Raw } \\
\text { score }\end{array}$} & \multicolumn{2}{|c|}{$\begin{array}{c}\text { Transformed } \\
\text { scores }\end{array}$} \\
\hline & $4-20$ & 0-100 & & $4-20$ & $0-100$ \\
\hline 6 & 4 & 0 & 3 & 4 & 0 \\
\hline 7 & 5 & 6 & 4 & 5 & 6 \\
\hline 8 & 5 & 6 & 5 & 7 & 19 \\
\hline 9 & 6 & 13 & 6 & 8 & 25 \\
\hline 10 & 7 & 19 & 7 & 9 & 31 \\
\hline 11 & 7 & 19 & 8 & 11 & 44 \\
\hline 12 & 8 & 25 & 9 & 12 & 50 \\
\hline 13 & 9 & 31 & 10 & 13 & 56 \\
\hline 14 & 9 & 31 & 11 & 15 & 69 \\
\hline 15 & 10 & 38 & 12 & 16 & 75 \\
\hline 16 & 11 & 44 & 13 & 17 & 81 \\
\hline 17 & 11 & 44 & 14 & 19 & 94 \\
\hline 18 & 12 & 50 & 15 & 20 & 100 \\
\hline
\end{tabular}

\begin{tabular}{|c|c|c|}
\hline \multicolumn{3}{|c|}{ DOMAIN 4} \\
\hline \multirow[t]{2}{*}{$\begin{array}{l}\text { Raw } \\
\text { score }\end{array}$} & \multicolumn{2}{|c|}{$\begin{array}{c}\text { Transformed } \\
\text { scores }\end{array}$} \\
\hline & $4-20$ & $0-100$ \\
\hline 8 & 4 & 0 \\
\hline 9 & 5 & 6 \\
\hline 10 & 5 & 6 \\
\hline 11 & 6 & 13 \\
\hline 12 & 6 & 13 \\
\hline 13 & 7 & 19 \\
\hline 14 & 7 & 19 \\
\hline 15 & 8 & 25 \\
\hline 16 & 8 & 25 \\
\hline 17 & 9 & 31 \\
\hline 18 & 9 & 31 \\
\hline 19 & 10 & 38 \\
\hline 20 & 10 & 38 \\
\hline 21 & 11 & 44 \\
\hline 22 & 11 & 44 \\
\hline 23 & 12 & 50 \\
\hline 24 & 12 & 50 \\
\hline 25 & 13 & 56 \\
\hline 26 & 13 & 56 \\
\hline 27 & 14 & 63 \\
\hline 28 & 14 & 63 \\
\hline 29 & 15 & 69 \\
\hline 30 & 15 & 69 \\
\hline 31 & 16 & 75 \\
\hline 32 & 16 & 75 \\
\hline 33 & 17 & 81 \\
\hline 34 & 17 & 81 \\
\hline 35 & 18 & 88 \\
\hline 36 & 18 & 88 \\
\hline 37 & 19 & 94 \\
\hline 38 & 19 & 94 \\
\hline 39 & 20 & 100 \\
\hline 40 & 20 & 100 \\
\hline
\end{tabular}

References

Bergner M, Bobbitt RA, Carter WB, Gilson BS. The Sickness Impact Profile: development and final revision of a health status measure. Med Care 1981; 19(8): 787-805. https://doi.org/10.1097/00005650-198108000-00001. 